\title{
Transabdominal Cerclage: Different Indications, Optimal Outcome. Two Case Reports
}

\author{
Yasser Sabr ${ }^{*}$ and Sara W Yousef \\ Department of Obstetrics and Gynecology, Collage of Medicine, King Saud University, Riyadh, Saudi Arabia
}

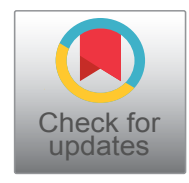

*Corresponding author: Yasser Sabr, Department of Obstetrics and Gynecology, Collage of Medicine, King Saud University, Riyadh, Saudi Arabia, E-mail: yasabr@gmail.com

\begin{abstract}
Transabdominal placement of a cerclage at the cervicoisthmic junction appears to be a safe and effective procedure for reducing the incidence of spontaneous pregnancy loss in selected patients with cervical insufficiency, we reported a case series of two woman with different indications for abdominal cerclage. Case 1 is a 25-years-old woman gravida 2 para 0 abortus 1 known case of hypoplastic upper vagina who had 2 vaginal repair (vaginostomy) and had abdominal cerclage for short cervix and delivered by caesarean section at 38 weeks a healthy baby boy. Case 2 is a 34-yearsold woman gravida 5 para 0 abortus 4 known case of diabetes mellitus type 2 and hypothyroidism, she has a history of 3 failed transvaginal cervical cerclage where all ended in miscarriages, so the fifth pregnancy was managed with transabdominal cerclage and she completed her pregnancy until 38 weeks of gestation and delivered a healthy baby boy by caesarean section.
\end{abstract}

\section{Keywords}

Cerclage, Cervical insufficiency, Transabdominal cerclage, Miscarriage, Preterm labor, Cervicoisthmic cerclage, Mullerian abnormality, Pregnancy

\section{Introduction}

Cervical insufficiency is defined as the inability of the uterine cervix to retain a pregnancy in the second trimester in the absence of clinical contractions, Labor, or both, and classical treatment involves transvaginal cervical cerclage. In some conditions, such as an extremely short, deformed or absent cervix, surgery needs to be done by transabdominal approach.

We reported 2 cases of different indications for abdominal cerclage where both had successful pregnancy and safe delivery with healthy babies.

\section{Case 1}

25-years-old woman gravida 2 para 0 abortus 1 known case of congenital hypoplastic upper vagina, for that she underwent multiple vaginal surgeries including vaginal septum resection, vaginoplasty (vaginostomy). After the procedures, Patient was unable to get pregnant for 1 year, so she came back and hysteroscopy with examination under anesthesia was done, which revealed stenosed upper vagina and very short cervix with normal uterine cavity. Following the procedure, the patient got pregnant spontaneously, and attended our clinic pregnant at 6 weeks gestational age for follow up. Ultrasound examination revealed short cervical length of $1.7 \mathrm{~cm}$ long and counselled regarding the Transabdominal cerclage since she had hypoplastic upper vagina and limited transvaginal access.

The patient had an uncomplicated transabdominal cerclage at 9 weeks gestation, she had a regular follow up in the clinic with ultrasound for the cervical length, cervical length surveillance was done at 15, 23, 25, 27, 30 and 35 weeks of gestation and the length was ranging between 2 and $2.2 \mathrm{~cm}$. Elective caesarean section was performed at 38 weeks with no complications. The abdominal cerclage was kept in place.

\section{Case 2}

34-years-old woman gravida 5 para 0 abortus 4 known case of diabetes mellitus type 2 on insulin and hypothyroidism on treatment, she has had a history of 4 second trimester miscarriages between 14 to 21 weeks gestation. Three of those miscarriages were managed by elective transvaginal cervical cerclage.

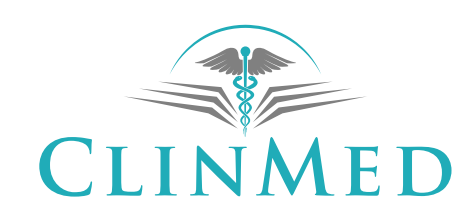

INTERNATIONAL LIBRARY
Citation: Sabr Y, Yousef SW (2018) Transabdominal Cerclage: Different Indications, Optimal Outcome. Two Case Reports. Int J Womens Health Wellness 4:067. doi.org/10.23937/2474-1353/1510067 Received: March 28, 2018: Accepted: April 14, 2018: Published: April 16, 2018

Copyright: (c) 2018 Sabr Y, et al. This is an open-access article distributed under the terms of the Creative Commons Attribution License, which permits unrestricted use, distribution, and reproduction in any medium, provided the original author and source are credited. 
She presented to maternal fetal clinic at 10 weeks gestation with ultrasound showing cervical length to be $1 \mathrm{~cm}$ and counselled about the transabdominal cerclage option due to her history of failed multiple transvaginal cervical cerclages. Patient opted to proceed with Transabdominal cerclage, which was performed at 10 weeks and 5 days of gestation. She had frequent uneventful antenatal care with cervical length surveillance showing the cervical length to be $1 \mathrm{~cm}$. Elective transverse lower segment caesarean section done at 38 weeks gestation.

\section{Discussion}

The American College of Obstetricians and Gynecologists defines cervical insufficiency as "The inability of the uterine cervix to retain a pregnancy in the second trimester in the absence of clinical contractions, Labor, or both". It may occur in a single pregnancy or recur in consecutive pregnancies [1].

Cervical abnormalities, either congenital or because of trauma, are a risk factor for structural cervical weakness [2].

Cerclage is one of the classical procedures which is performed to reduce pregnancy loss/preterm birth in women with cervical insufficiency:

- Women with cervical insufficiency based on multiple prior second trimester losses and/or preterm births are potential candidates for a 'history-indicated' cerclage, which is best placed at 12 to 14 weeks of gestation [3].

- Women with singleton pregnancy, prior preterm birth, and a short cervical length (e.g., $<25 \mathrm{~mm}$ ) on transvaginal ultrasound examination at 16 to 23 weeks of gestation are potential candidates for an 'ultrasound-indicated' cerclage [4,5].

- Women with cervical insufficiency based on a dilated cervix on a digital or speculum examination at 16 to 23 weeks of gestation are potential candidates for a 'physical exam-indicated' cerclage [6].

Most cerclages are placed via a transvaginal approach. The transabdominal approach is more invasive but allows higher placement since the transabdominal cerclage can be placed at the cervicoisthmic portion of the uterus, while transvaginal cerclages often end up distal to the internal os.

Given the increased morbidity of any transabdominal procedure compared with a transvaginal procedure, most experts recommend reserving the transabdominal approach for women with cervical insufficiency who meet one (or both) of the following criteria:

- Failed to deliver a healthy newborn after at least one previous elective transvaginal cerclage (i.e., does not include a rescue cerclage performed for advanced cervical dilation on physical examination).
- Are unable to undergo a transvaginal procedure because an extremely short or absent cervix, amputated cervix, marked cervical scarring, or cervical defect make it technically impossible to perform [7].

In a systematic review of observational studies that evaluated pregnancy outcome after laparoscopic versus open transabdominal cerclage, overall neonatal survival was about 90 percent for both procedures; however, the laparoscopic group had higher survival when first trimester losses were excluded (96.5 versus 90.1 percent), a higher rate of deliveries after 34 weeks (82.9 versus 76 percent), and lower rates of deliveries at 23.0 to 33.6 weeks (6.8 versus 14.8 percent) and second-trimester losses (3.2 versus 7.8 percent). Intraoperative and perioperative complications were similar for the two approaches [8].

Either cerclage placement after conception once fetal viability has been established or preconception transabdominal cerclage in patients planning to conceive who meet criteria are acceptable options. There is no consensus as to the best approach [9].

In patients presenting in early pregnancy, a transabdominal cerclage should be placed in the late first trimester to early second trimester as the risk of miscarriage is lower than earlier in gestation, major structural anomalies can be excluded by ultrasound, early aneuploidy screening can be performed, and the uterus is not too large to make it technically challenging [10].

Delivery after transabdominal cerclage is by caesarean at 37 to 39 weeks of gestation, or immediately at the onset of regular uterine contractions. The infant is extracted through a hysterotomy incision made above the stitch; the stitch can then be removed or, if future pregnancies are planned, it is left in place [11,12].

In conclusion we might prefer a transabdominal cervicoisthmic cerclage in special cases like women with cervical insufficiency who have either failed at least one previous elective transvaginal cervical cerclages or in whom a transvaginal cervical cerclage is technically impossible to perform due to an extremely short or absent cervix, or with vaginal or cervical defect, In these settings, a transabdominal approach might result in better birth outcomes than the transvaginal approach, thus justifying its greater morbidity.

\section{Conflict of Interest}

The authors declares that there is no conflict of interest regarding the publication of this paper.

\section{References}

1. American College of Obstetricians and Gynecologists (2014) ACOG Practice Bulletin No.142: Cerclage for the management of cervical insufficiency. Obstet Gynecol 123: 372-379.

2. Vyas NA, Vink JS, Ghidini A, Pezzullo JC, Korker V, et al. (2006) Risk factors for cervical insufficiency after term delivery. Am J Obstet Gynecol 195: 787-791. 
3. (1993) Final report of the Medical Research Council/Royal College of Obstetricians and Gynaecologists multicentre randomised trial of cervical cerclage. MRC/RCOG working party on Cervical Cerclage. Br J Obstet Gynaecol 100: 516523.

4. Berghella V, Odibo AO, To MS, Rust OA, Althuisius SM (2005) Cerclage for short cervix on ultrasonography: Meta-analysis of trials using individual patient-level data. Obstet Gynecol 106: 181-189.

5. Berghella V, Keeler SM, To MS, Althuisius SM, Rust OA, et al. (2010) Effectiveness of cerclage according to severity of cervical length shortening: A meta-analysis. Ultrasound Obstet Gynecol 35: 468-473.

6. Ehsanipoor RM, Seligman NS, Saccone G, Szymanski LM, Wissinger C, et al. (2015) Physical examination-indicated cerclage: A systematic review and meta-analysis. Obstet Gynecol 126: 125-135.

7. Zaveri V, Aghajafari F, Amankwah K, Hannah M (2002) Abdominal versus vaginal cerclage after a failed transvaginal cerclage: A systematic review. Am J Obstet Gynecol 187: 868-872.

8. Moawad GN, Tyan P, Bracke T, Abi Khalil ED, Vargas V, et al. (2018) Systematic review of transabdominal cerclage placed via laparoscopy for the prevention of preterm birth. J Minim Invasive Gynecol 25: 277-286.

9. Burger NB, Einarsson JI, Brölmann HA, Vree FE, McElrath TF, et al. (2012) Preconceptional laparoscopic abdominal cerclage: A multicenter cohort study. Am J Obstet Gynecol 207: 273.e1-273.e12.

10. Joung EJ, Go EB, Kwack JY, Kwon YS (2016) Successful term delivery cases of trans-abdominal cervicoisthmic cerclage performed at more than 18 weeks of gestation. Obstet Gynecol Sci 59: 319-322.

11. Hawkins E, Nimaroff M (2014) Vaginal erosion of an abdominal cerclage 7 years after laparoscopic placement. Obstet Gynecol 123: 420-423.

12. Hortenstine JS, Witherington R (1987) Ulcer of the trigone: A late complication of cervical cerclage. J Urol 137: 109-110. 